\title{
Formation of Transient Inappropriate Sensorimotor Synapses in Developing Rat Spinal Cords
}

\author{
Bradley S. Seebach ${ }^{\mathrm{a}}$ and Lea Ziskind-Conhaim \\ Department of Physiology and Center for Neuroscience, University of Wisconsin Medical School, Madison, Wisconsin \\ 53706
}

The specificity of the convergence of primary afferent projections from ankle muscles onto motoneurons that innervate these muscles was studied in lumbar spinal cords of embryonic and neonatal rats. The connectivity pattern was determined for each motoneuron by stimulating nerves from ankle flexor and extensor muscles and recording the synaptic potentials in identified motoneurons. In mature mammals, muscle spindle afferents make direct excitatory connections with motoneurons that innervate homonymous and synergistic muscles, and with interneurons that inhibit motoneurons innervating antagonistic muscles. Therefore, appropriate primary afferent-motoneuron connections were identified when stimulation of homonymous and synergistic muscle nerves evoked monosynaptic EPSPs. Two criteria were used for identification of EPSPs as monosynaptic potentials: (1) the monosynaptic potentials were evoked at the shortest latency, and (2) they were more resistant to fatigue by repetitive nerve stimulation than the longer-latency, polysynaptic potentials. Functionally inappropriate primary afferent-motoneuron contacts were identified when stimulation of an antagonistic muscle nerve produced monosynaptic EPSPs instead of polysynaptic IPSPs in homonymous motoneurons.

At days $18-21$ of gestation, about $30 \%$ of motoneurons were innervated by primary afferents of antagonist muscles. Such functionally inappropriate synapses persisted at birth, but their percentage was significantly reduced within 3-5 d after birth. The findings suggested that in the developing spinal cord of the rat, a significant percentage of motoneurons were initially innervated by inappropriate primary afferents of antagonistic muscles. The decrease in percentage of such inappropriate connections was correlated temporally with the increase in the frequency of spontaneous activity and the onset of myelination.

[Key words: synaptogenesis, sensorimotor synapse, specific innervation, inappropriate synapse, developing spinal cord, rat embryo]

Received Aug. 30, 1993; revised Jan. 13, 1994; accepted Feb. 2, 1994

We thank Drs. Eric Frank and Peter Wenner for technical advice, Drs. Peter Lipton and Phil Smith for critical comments on the manuscript, Ms. Carol Dizack and Mr. Terry Stewart for help in illustration and photography, and Mrs. Sue Krey for typing. This work was supported by NRSA Postdoctoral Fellowship HD07118-15 to B.S.S and NINDS Research Career Development Award NS01314, and NIH Grant NS23808 to L.Z.-C.

Correspondence should be addressed to Lea Ziskind-Conhaim, Department of Physiology, 129 SMI, 1300 University Avenue, University of Wisconsin Medical School, Madison, WI 53706.

aPresent address: Department of Neurobiology, SUNY-Stony Brook, 550 Life Science Building, Stony Brook, NY 11794.

Copyright (C) 1994 Society for Neuroscience $0270-6474 / 94 / 144520-09 \$ 05.00 / 0$
The function of the nervous system is based on stereotyped patterns of synaptic connections between specific neurons. Examples of such precise interactions between central neurons are the spinal reflex pathways, which have been studied extensively in mature mammals (reviewed by Burke, 1990; Munson, 1990). In stretch reflex, stretch-sensitive sensory neurons that supply muscle spindles make specific connections with various groups of spinal motoneurons. Primary afferents of a particular muscle monosynaptically excite two groups of motoneurons: those that innervate the same muscle (homonymous) and those that contact muscles with related function (synergists). These primary afferents also project onto interneurons that inhibit motoneurons innervating muscles with opposite function (antagonists) (Eccles et al., 1957a; Mendell and Henneman, 1971; Binder, 1980; Kirkwood and Sears, 1982; Fritz et al., 1989). Therefore, a specific primary afferent monosynaptically excites homonymous and synergistic motoneurons and disynaptically inhibits antagonistic motoneurons. Similar patterns of synaptic contacts between muscle spindle afferents and motoneurons have also been described in the spinal cords of mature frogs (Frank and Westerfield, 1982).

In the spinal cord of rat embryos, dorsal root afferents establish monosynaptic contacts with lumbar motoneurons at days 17-18 of gestation (Kudo and Yamada, 1985, 1987; ZiskindConhaim, 1990). The physiological and pharmacological properties of these initial synapses have been characterized (Saito, 1979; Ziskind-Conhaim, 1990; Wu et al., 1992), but little was known about the initial pattern of convergence of muscle afferent projections onto embryonic motoneurons that innervate muscles of synergistic and antagonistic functions. Preliminary results of a study that examined the specificity of sensorimotor innervation in the spinal cords of neonatal rats imply that, at 4-10 d after birth, appropriate contacts are formed between primary afferents of flexor and extensor muscles and their specific motoneurons (Jahr and Yoshioka, 1986). Only a small number of experiments, designed to analyze the specificity of innervation, were conducted in this study.

Intracellular recordings have been used in extensive studies that examined the development of functional synapses between muscle afferents and spinal motoneurons in frogs (Frank and Westerfield, 1983) and in chicks (Eide et al., 1982; Lee et al., 1988; Lee and O'Donovan, 1991 ; Mendelson and Frank, 1991). In the developing spinal cord of the frog, afferents of the arm muscles (triceps) generate larger EPSPs in triceps motoneurons than in either pectoral or subscapular motoneurons that innervate the forelimb. Those findings suggested that, like the synaptic organization in mature frogs (Frank and Westerfield, 1982), the growing muscle afferents established monosynaptic contacts with homonymous and synergistic motoneurons but not with 
motoneurons innervating unrelated muscles. In the chick spinal cord, the pattern of sensorimotor connectivity does not change during development, which implies that appropriate synapses are formed from the onset. However, because stretch reflex pathways had not been characterized in adult chickens, it is uncertain whether the pattern of innervation in developing chicks is similar to that of adult animals (Lee and O'Donovan, 1991).

The objective of our study was to determine the specificity of the initial monosynaptic connections between afferent projections and the motoneurons that innervate ankle flexor and extensor muscles of embryonic and neonatal rats. The functional organization of the sensorimotor synaptic contacts at the time that initial monosynaptic connections were formed was compared to their organization after birth when rats began making simple coordinated leg movements. Our findings suggested that both appropriate and inappropriate synapses were formed in spinal cords of rat embryos, but within a week after birth most muscle afferent-motoneuron contacts were appropriate.

A brief report of some of the results has been published (Seebach and Ziskind-Conhaim, 1992).

\section{Materials and Methods}

Preparation of isolated spinal cord with hindlimb nerves. Sprague-Dawley rat embryos at days 19-21 of gestation (E19-E21; birth is at E21E22) and 0-5-d-old postnatal rats (P0-P5) were used in this study. Pregnant rats were lightly anesthetized with ether and decapitated, and the embryos were quickly removed and placed in cold solution, following the procedure described by Ziskind-Conhaim (1988a, 1990). Neonates were anesthetized with hypothermia. Ventral laminectomy exposed the lumbosacral spinal cord without damaging the ventral and dorsal roots. The spinal cord was hemisected sagittally, and the attached lumbosacral plexus, sciatic nerve, and individual hindlimb muscle nerves were dissected free (Fig. 1). The hemisected spinal cord with intact muscle nerves was pinned on its medial surface to a Sylgard-coated recording chamber, and five nerves were drawn into tight-fitting glass stimulating electrodes. The preparation was continuously perfused with oxygenated $(95 \% \mathrm{O}, 5 \% \mathrm{CO}$ ) recording solution at room temperature $\left(21-24^{\circ} \mathrm{C}\right)$. The recording solution contained (in $\left.\mathrm{mm}\right) \mathrm{NaCl}, 116.4 ; \mathrm{KCl}$, 5.4; $\mathrm{CaCl}_{2}, 4.0 ; \mathrm{MgSO}_{4}, 1.3 ; \mathrm{NaHCO}_{3}, 26.2 ; \mathrm{NaHPO}_{4}, 0.92 ;$ glucose, 11.0. The solution was gassed with $95 \% \mathrm{O}_{2}, 5 \% \mathrm{CO}_{2}(\mathrm{pH} 7.2-7.4)$. The following substances were added to the recording solution at known concentrations: 2-amino-5-phosphonovaleric acid (APV), 6-cyano-7nitroquinoxaline-2,3-dione (CNQX), strychnine, and bicuculline (Research Biochemicals, Inc.)

Two groups of lower hindlimb (calf) muscle nerves were used: (1) the ankle extensors and their synergists the digit flexors, and (2) the ankle flexors and their synergists the digit extensors. The first group included lateral gastrocnemius (LG), soleus (SOL), medial gastrocnemius (MG), flexor digitorum superficialis (FDS), and flexor digitorum profundus (FDP), and the second group included tibialis anterior (TA), and extensor digitorum longus (EDL). Because myelination of peripheral nerves begins a few days after birth (Peters and Muir, 1959; Ziskind-Conhaim, $1988 \mathrm{~b}$ ), most of the nerves used in this study were still unmyelinated. As a result, it was sometimes difficult to separate the LG and SOL branches of the common lateral gastrocnemius/soleus nerve (LG/SOL). In embryonic rats this common nerve was often drawn into one stimulating electrode.

Electrophysiology. Motoneurons in $\mathrm{L}_{4}-\mathrm{L}_{6}$ were impaled with microelectrodes (90-180 M $)$ ) filled with $3 \mathrm{~m}$ potassium acetate, and data were collected only from motoneurons with stable membrane resting potentials ( $>30 \mathrm{~min}$ ) more negative than $-55 \mathrm{mV}$. The average resting potential was $-67.4 \pm 4.2 \mathrm{mV}(n=88$ motoneurons, 39 rats $)$. Motoneuron resting potentials were similar in embryos and neonates (also 7iskindConhaim et al., 1993).

The diameter of the stimulating electrodes was adjusted at each age to provide a tight fit around the nerves. Nerve stimulation that consisted of brief square pulses $(0.3 \mathrm{msec})$ and intensities of $2.5-5 \mathrm{~V}$ generated short-latency synaptic potentials. Five consecutive synaptic potentials were averaged to minimize the contribution of sponlaneous potentials. Motoneurons were identified by antidromic nerve stimulation. The stimulus intensity required to generate antidromic action potentials in

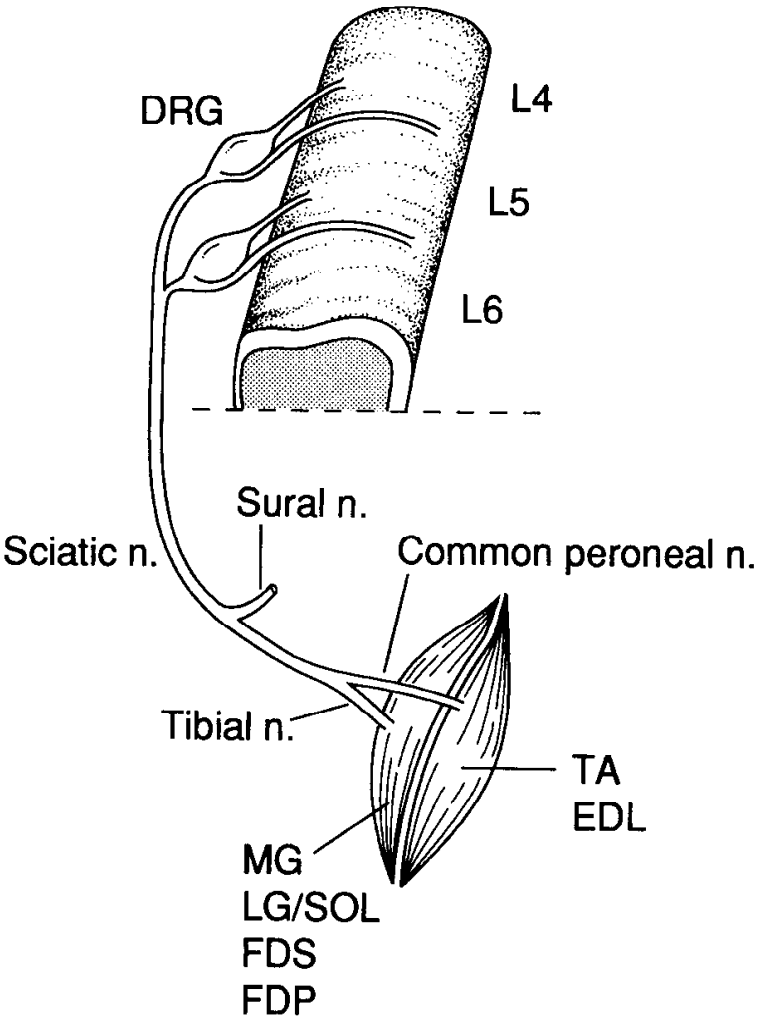

Figure 1. Diagram of spinal cord-hindlimb preparation. The dorsal root ganglia $(D R G)$ and the ventral and dorsal roots remained attached to the hemisected lumbar spinal cord. The major nerves innervating the flexor and extensor lower hindlimb muscles are the sciatic, sural, tibial, and common peroneal nerves. The nerves of the following muscles were used in this study: the medial gastrocnemius $(M G)$, lateral gastrocnemius/soleus $(L G / S O L)$, flexor digitorum superficialis $(F D S)$ that extended the ankle, the flexor digitorum profundus $(F D P)$ and $F D S$ that flexed the digits, the tibialis anterior $(T A)$ which flexed the ankle, and the extensor digitorum longus $(E D L)$ that extended the digits. The tibial nerve was separated into four nerves: $M G, L G / S O L, F D S$, and $F D P$. The common peroneal was separated into two nerves: $T A$ and $E D L$. The nerves were drawn into the stimulating electrodes, and motoneurons in segments $L_{6}-L_{6}$ were impaled for intracellular recordings.

motoneurons was often more than twofold higher than that required to evoke orthodromic synaptic potentials. To determine whether stimulating currents applied to one suction electrode could induce a nonspecific excitation of several nerves, the stimulating electrodes were placed close to the nerves but without drawing the nerves into them. Under these conditions, electrical stimuli at intensities $<50 \mathrm{~V}$ failed to generate potentials in motoneurons. Thercforc, it is unlikely that current spread between electrodes can nonselectively stimulate several nerves.

Nerve-evoked potentials were displayed on a digital analyzer (Data 6000 , Data Precision) and stored on magnetic disks for later analysis and plotting (Hewlett-Packard pen recorder).

Rats were divided into three age groups: E19-E21 ( $n=21$ motoneurons), $\mathrm{P} 0-\mathrm{P} 2$ ( $n=34$ motoneurons), and $\mathrm{P} 3-\mathrm{P} 5$ ( $n=33$ motoneurons). The statistical significance of the difference between the percentages of motoneurons with inappropriate synapses at various ages was determined using the $\chi^{2}$ test of independence.

\section{Results}

Nerve-evoked antidromic and orthodromic potentials

To identify the impaled motoneuron and the afferents that projected onto it, five nerves of extensor and flexor muscles were stimulated. Nerve stimulation generated three types of potentials: antidromic action potentials, electrotonic potentials, and 


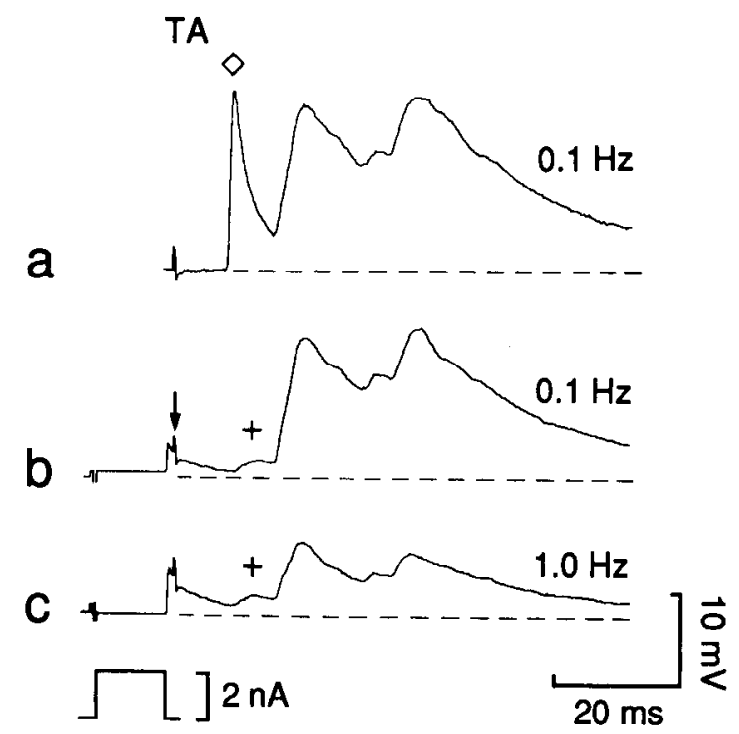

Figure 2. Antidromic and orthodromic potentials evoked in a TA motoneuron at P5. a, At $0.1 \mathrm{~Hz}$, nerve stimulation generated an initial segment action potential (diamond) followed by synaptic potentials that were blocked by a mixture of glutamate antagonists (APV and CNQX; not shown). $b$, To block the antidromic action potential, the motoneuron was briefly depolarized (not shown) before the TA nerve was stimulated (arrow). The soma action potential was subtracted from the trace. Inhibition of antidromic action potential unmasked the electrotonic potential (cross), which was not blocked by the mixture of APV and CNQX. $c$, At higher stimulus frequency $(1.0 \mathrm{~Hz})$ the amplitude of the synaptic potential but not the electrotonic potential was reduced. All records are averages of five nerve-evoked potentials generated at $0.1 \mathrm{~Hz}(a, b)$ and $1.0 \mathrm{~Hz}(c)$. The resting membrane potential $(-61 \mathrm{mV})$ is indicated by the dashed line.

orthodromic synaptic potentials (Fig. 2). Motoneuron identiflcation was based on the production of antidromic action potentials that were evoked only in response to homonymous nerve stimulation. The latency between nerve stimulation and the antidromic propagation of an action potential into motoneuron somata ranged between 10 and $30 \mathrm{msec}$. The long and variable latencies were probably due to the slow and variable conductance velocities of immature nerves at different stages of myelination (Ziskind-Conhaim, 1988b).

Short-latency synaptic potentials were generated at nerve stimulus intensities of 2.5-5 V, which were 1.5 times the threshold intensity. They were generated $3-7 \mathrm{msec}$ after antidromic action potentials were evoked (see below). Nerves that did not produce short-latency potentials at low stimulus intensities often evoked long-latency potentials at higher stimulus intensities. These results suggested that, similar to the pattern of synaptic activation in mature mammals, primary afferents (group I) were activated at lower stimulus intensitics than afferents of groups II and III (reviewed by Baldissera et al., 1981).

Short-latency synaptic potentials evoked by homonymous nerve stimulation were sometimes masked by the antidromic action potential (Fig. 2). To record such synaptic potentials, the propagation of the antidromic potential was blocked by induction of somatic action potential 5-15 msec prior to nerve stimulation. The soma action potential was evoked by a brief ( 10 msec) intracellularly injected depolarizing current and presumably collided with the antidromic potential without affecting the generation of electrotonic and synaptic potentials (Fig. 2b).

Stimulation of homonymous nerves generated short-latency electrotonic potentials in $20 \%$ of the motoneurons $(n=18)$. Unlike the short-latency synaptic potentials, the amplitude of these electrotonic potentials was not affected by repetitive nerve stimulation (1.0 Hz; Fig. $2 c ; n=18$ ), low $\mathrm{Ca}^{2+} /$ high $\mathrm{Mg}^{2+}$ solution ( $1 \mathrm{mM} \mathrm{Ca}^{2+}, 10 \mathrm{mM} \mathrm{Mg}^{2+} ; n=3$ ), or antagonists of glutamate receptors, which blocked excitatory synaptic transmission $(n=3)$. Such potentials can be produced in response to antidromic nerve stimulation, which excites electrically coupled homonymous but not antagonistic motoneurons (Walton and Navarrete, 1991).

\section{Identification of mono- and polysynaptic potentials}

To determine the specificity of synapses between muscle afferents and motoneurons, it was essential to distinguish between nerve-evoked monosynaptic EPSPs and polysynaptic IPSPs. Furthermore, stimulation of homonymous and synergistic nerve muscles always generated both mono- and polysynaptic EPSPs, and criteria were established to distinguish between them. Nerveevoked synaptic potentials were classified as monosynaptic only if they were both induced at the shortest latency and were suppressed less by repetitive stimulation than the long-latency potentials.

To estimate the synaptic delays of monosynaptic potentials, we measured the latency between antidromic action potential and the short-latency potential. Such delays ranged from 3 to 7 msec, similar to the delays of monosynaptic potentials in neonatal rats (Kudo and Yamada, 1985) and embryonic chicks (Mendelson and Frank, 1991). $\Lambda$ more reliable method for estimating the synaptic delay is to measure the delay between dorsal root volleys and the evoked synaptic potentials (Kuno, 1964; Mendell and Henneman, 1971; Eide et al., 1982; Mendelson and Frank, 1991). However, we could not use this technique because it was difficult to record the small extracellular potentials $(<0.2 \mathrm{mV}$ ) without damaging the nonmyelinated axons.

The attenuating effect of repetitive nerve stimulation on the amplitude of synaptic potentials was the second criterion used in our study to distinguish between mono- and polysynaptic potentials (Berry and Pentreath, 1976; Lee and O'Donovan, 1991). Repetitive stimulation can effectively fatigue synaptic transmission, and the magnitude of this suppression increases with the number of stimulated synapses. Therefore, attenuation of synaptic potentials was more effective in polysynaptic than monosynaptic pathways. In our study, repetitive stimuli at frequencies $>0.2 \mathrm{~Hz}$ reduced the amplitude of both the short- and long-latency potentials, but they reduced the amplitude of the long-latency potentials by about $20-40 \%$ more than the amplitude of the short-latency potentials. The frequency at which repetitive stimuli attenuated the synaptic potentials varied with developmental ages. For example, at E19-E21, nerve stimulation at $0.5 \mathrm{~Hz}$ was more effective in reducing the amplitude of the long-latency potentials than the amplitude of the short-latency potentials (Fig. 3a). However, at P0-P5, this differential resistance to fatigue by the frequency of nerve stimulation was apparent only at $1.0 \mathrm{~Hz}$ (Fig. $3 b$ ).

If the shortest-latency potential was more resistant to fatigue by repetitive nerve stimulation than the long-latency potential, the potential was classified as monosynaptic. However, if similar attenuation was recorded for both short- and long-latency potentials, both potentials were considered polysynaptic.

Another method that can be used to distinguish between monoand polysynaptic potentials is based on their differential sen- 
a

homonymous, EDL

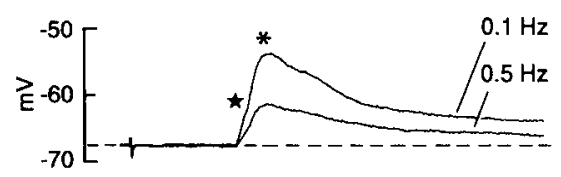

antagonist, FDS

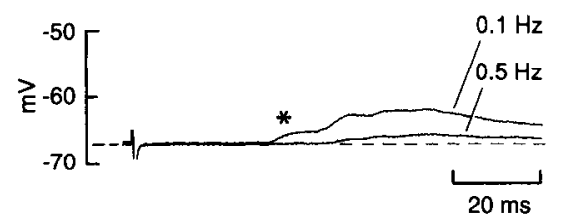

b

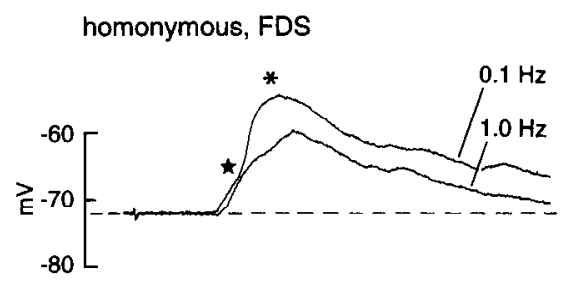

antagonist, TA

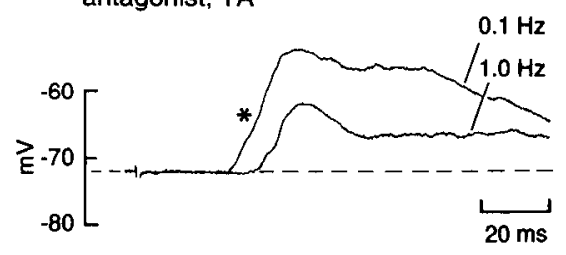

Figure 3. Repetitive nerve stimulation was more effective in suppressing long-latency, polysynaptic potentials than short-latency, monosynaptic potentials. $a$, In an EDL motoneuron at E21, stimulation of the homonymous nerve EDL produced mono- and polysynaptic potentials, while stimulation of the nerve of the antagonistic muscle FDS generated only polysynaptic potentials. Stimulation of the EDL nerve at $0.5 \mathrm{~Hz}$ reduced the peak amplitude of the monosynaptic potentials (star) by $40 \%$ while the peak amplitude of the polysynaptic potentials (asterisk) was reduced by $60 \%$. The amplitude of the polysynaptic potentials generated by the FDS nerve was reduced by $75 \%$. $b$, In an FDS motoneuron at P3, the amplitude of the monosynaptic potentials generated by stimulation of the FDS nerve (star) was not reduced at $1.0 \mathrm{~Hz}$, while the peak amplitude of polysynaptic potentials (asterisk) was reduced by $40 \%$. The peak amplitude of the polysynaptic potentials generated by the antagonistic nerve TA was reduced by $45 \%$.

sitivity to the extracellular concentration of divalent ions (Berry and Pentreath, 1976). High concentrations of divalent cations reduced the amplitude of polysynaptic potentials more than that of monosynaptic potentials in neonatal rats (Jahr and Yoshioka, 1986), but their effect was inconsistent in chick motoneurons (Lee and O'Donovan, 1991). Furthermore, in our preliminary experiments, high-divalent solution ( $4 \mathrm{~mm} \mathrm{Ca}^{2+}, 8 \mathrm{mM} \mathrm{Mg}^{2+}$ ) did not consistently reduce the amplitude of the synaptic potentials $(n=3)$, while $1 \mathrm{~mm} \mathrm{Ca}^{2+}, 10 \mathrm{~mm} \mathrm{Mg}^{2+}$ solution effectively reduced both the short- and long-latency potentials ( $n=$ 3).

\section{EPSPS and IPSPS}

In the spinal cord of embryonic and neonatal rats, dorsal rootevoked potentials consist of EPSPs and depolarizing IPSPs (Thakahashi, 1984; Jahr and Yoshioka, 1986). To identify the inhibitory component, all motoneurons were transiently depolarized to potentials more positive than the estimated equilibrium potential for $\mathrm{Cl}^{-}$(Gao and Ziskind-Conhaim, 1992; Wu et al., 1992). In immature motoneurons, the depolarizing IPSPs were long-latency, polysynaptic potentials that reversed at membrane potentials of -45 to $-60 \mathrm{mV}$ (Fig. 4). Because the polysynaptic potentials consisted of EPSPs and IPSPs, motoneuron depolarization did not always reverse the polarity of the polysynaptic potentials. Membrane depolarization did not significantly change the amplitude of the short-latency potentials, indicating that these were monosynaptic EPSP (Figs. 4, 5; see also Ziskind-Conhaim, 1990). When a motoneuron was depolarized to action potential threshold, the monosynaptic EPSP triggered an action potential (Figs. 5, 6).

To distinguish further between EPSPs and depolarizing IPSPs, the EPSPs were blocked with APV $(20 \mu \mathrm{M})$ and CNQX $(10 \mu \mathrm{M})$,
Tibial $n$. (homonymous/synergist)

\section{Common peroneal $n$. (antagonist)}

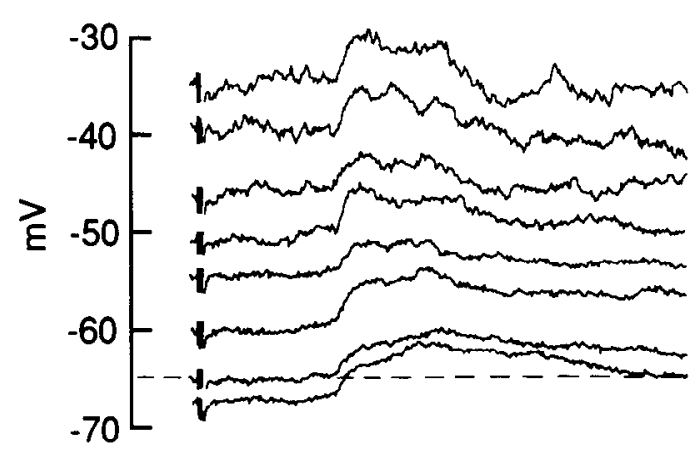

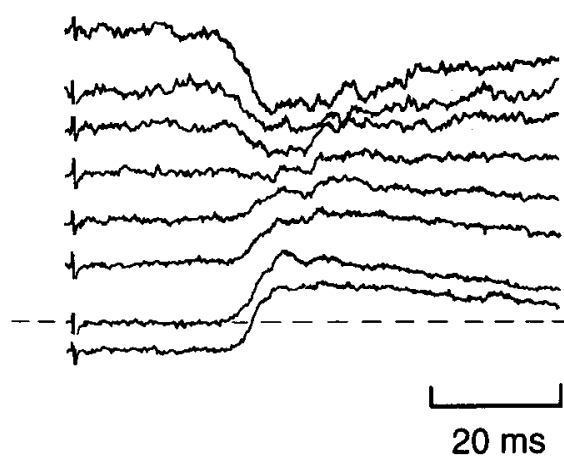

Figure 4. Membrane depolarization reversed the potentials produced by the antagonistic (common peroneal), but not the synergistic (tibial) nerve in a P0 motoneuron. At resting potential, both nerves generated depolarizing potentials, but only the potentials produced by the common peroneal nerve reversed at around $-50 \mathrm{mV}$. These findings suggested that EPSPs were generated by the tibial nerve, while depolarizing IPSPs were produced by stimulation of the common peroneal nerve. 


\section{MG}

\section{a ANTIDROMIC ACTION POTENTIALS}

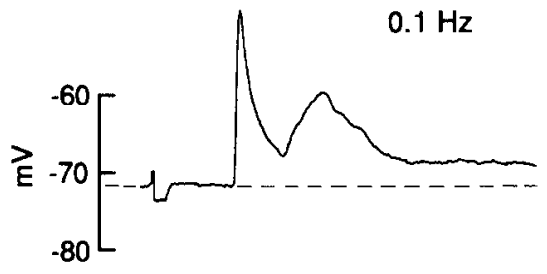

b

Figure 5. Appropriate synaptic connections between an MG motoneuron and primary afferent projections at P3. $a$, At $0.1 \mathrm{~Hz}$, antidromic action potentials and orthodromic synaptic potentials were generated, but at $10 \mathrm{~Hz}$ only the antidromic action potential was produced. $b$, Low-intensity stimuli of $\mathrm{MG}$ and SOL nerves generated monosynaptic potentials (star). During membrane depolarization to $-54 \mathrm{mV}$, the monosynaptic potentials triggered action potentials (truncated) with prolonged afterhyperpolarizing potentials. Membrane depolarization to $-54 \mathrm{mV}$ reversed the polysynaptic depolarizing potentials generated by the nerve of the weak synergistic muscle FDP, and the nerves of the antagonistic muscles EDL and TA. All records are averages of five nerve-evoked potentials generated at 0.1 $\mathrm{Hz}$. The resting membrane potential is indicated by the dashed line, and depolarization to $-54 \mathrm{mV}$ is marked by the dotted line.

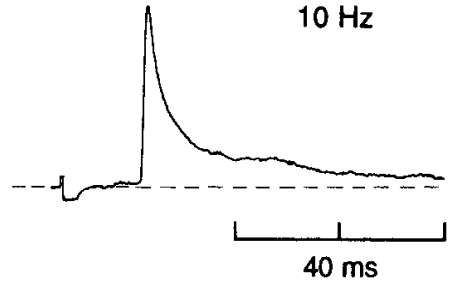

ORTHODROMIC POTENTIALS
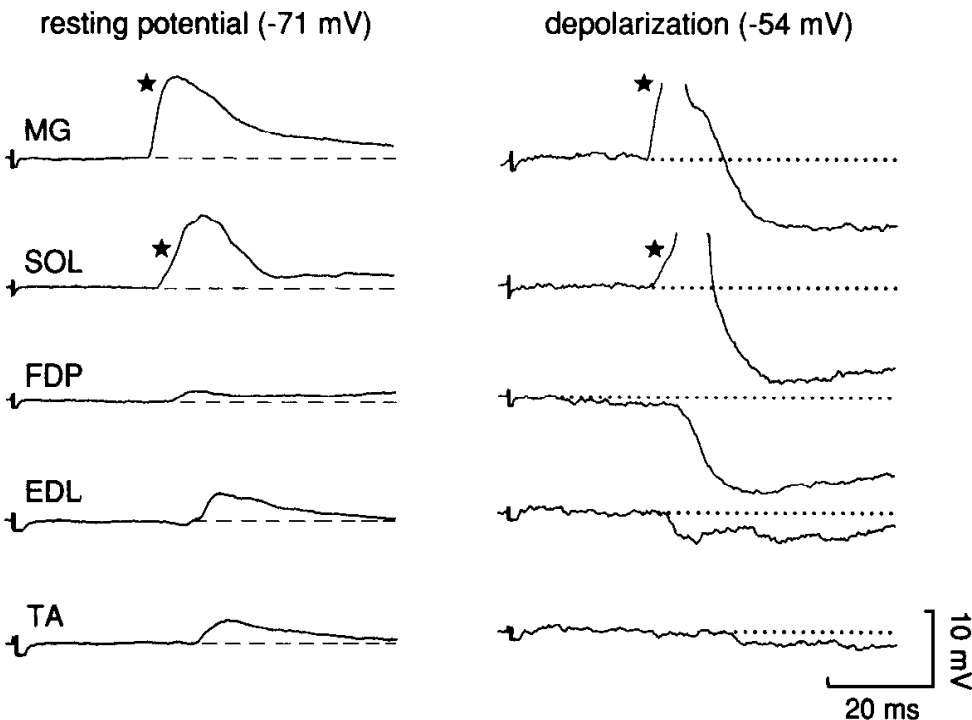

antagonists of NMDA and non-NMDA receptors, respectively. However, blocking glutamate-induced synaptic transmission eliminated both EPSPs and IPSPs, suggesting that inhibitory interneurons were activated by glutamate-mediated pathways. The IPSPs that reversed during membrane depolarization were sclcctively blocked by strychnine $(10 \mu \mathrm{M})$ or bicuculline $(20 \mu \mathbf{M}$; $n=6$ ), antagonists of glycine and $\mathrm{GABA}_{\mathrm{A}}$ receptors, respectively. Within $20 \mathrm{~min}$ of antagonist application, the disinhibition of excitatory synapses induced a significant increase in the amplitude and duration of polysynaptic potentials, which resulted in a prolonged repetitive firing (not shown, but see $\mathrm{Wu}$ et al., 1992).

\section{Identification of appropriate and inappropriate monosynaptic connections between primary afferents and motoneurons}

To determine the specificity of afferent projections onto identified motoneurons, five nerves of homonymous, synergistic, and antagonistic muscles were stimulated, and monosynaptic EPSPs were distinguished from polysynaptic EPSPs and IPSPs. Monosynaptic innervation was regarded appropriate if afferents monosynaptically excited homonymous and synergistic motoncurons and polysynaptically inhibited antagonistic motoneurons. For example, an MG motoneuron was monosynaptically innervated by MG and SOL afferents and polysynaptically contacted by afferents of the antagonistic muscles EDL and TA (Fig. 5). Stimulation of the nerve of the weak synergistic muscle FDP generated IPSPs instead of EPSPs, probably due to stimulation of the tendon organ afferents (group Ib) that polysynaptically inhibited synergistic motoneurons (Eccles et al., 1957b).

Functionally inappropriate innervation was identified when a motoneuron was monosynaptically innervated by afferents of antagonistic muscle. For example, the monosynaptic innervation of $\mathrm{MG}$ motoneuron by afferents of the antagonistic muscle TA (Fig. 6) was regarded as inappropriate. In an appropriate innervation of another MG motoneuron (Fig. 5), stimulation of the TA nerve generated polysynaptic IPSPs rather than monosynaptic EPSPs (Fig. 6).

Appropriate and inappropriate monosynaptic potentials had similar latencies (Fig. 7), indicating that inappropriate synapses had been identified correctly. Twenty-seven percent of motoneurons received functionally inappropriate synapses, and $98 \%$ of these were between afferents of antagonistic ankle muscles and motoneurons innervating homonymous ankle muscles. Only two of the inappropriate connections were between afferents of weak antagonistic digit muscles and motoneurons of ankle muscles.

In $83 \%$ of the motoneurons that received inappropriate monosynaptic innervation, appropriate synapses were also formed between afferents of homonymous nerves and their motoneurons (Fig. 6h). For example, the MG motoneuron that was inappropriately innervated by primary afferents of the antagonistic muscle TA, was also innervated by afferents of the 
appropriate innervation

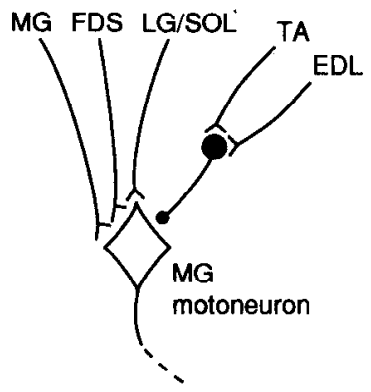

MG

b resting potential $(-65 \mathrm{mV})$
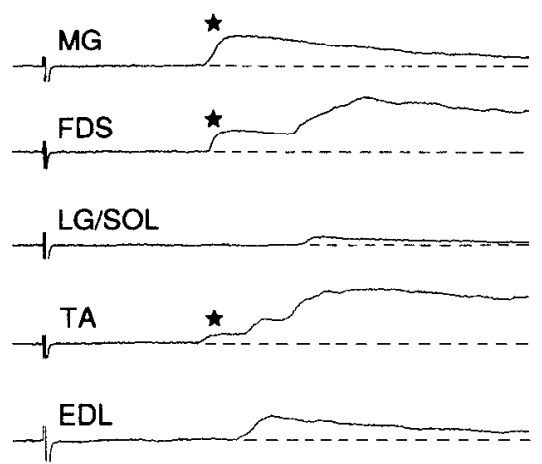

inappropriate innervation

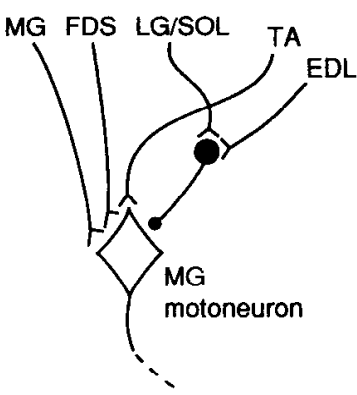

C

depolarization $(-51 \mathrm{mV})$
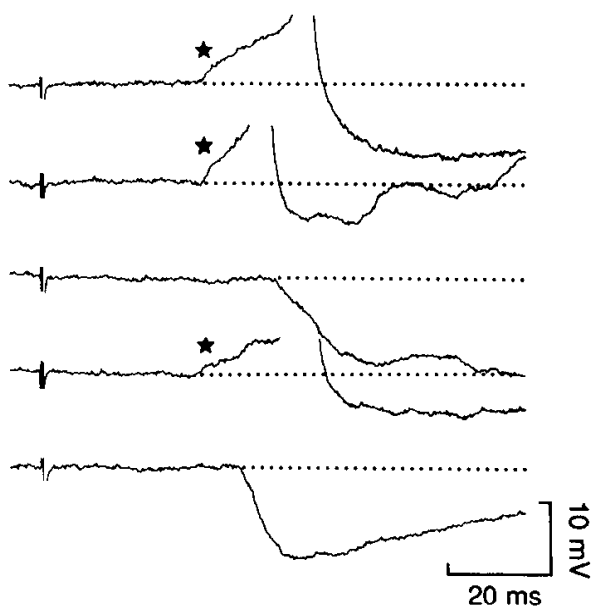

Figure 6. Inappropriate connection between afferents of antagonist muscle nerve and an $\mathrm{MG}$ motoneuron at P0. a, A diagram of an MG motoneuron with appropriate afferent projections of MG, FDS, and LG/SOL nerves (left) and inappropriate contacts between afferents of the antagonistic muscle TA and the motoneuron (right). Inhibitory interneurons are indicated by the solid circles. $b$, Stimulation of the homonymous MG, the synergistic FDS, and the antagonistic TA muscle nerves evoked monosynaptic potentials (star), while the synergistic LG/SOL, and the antagonistic EDL generated polysynaptic potentials. $c$, During motoneuron depolarization to $-51 \mathrm{mV}$, the monosynaptic potentials reached action potential threshold, and action potentials (truncated) with prolonged afterhyperpolarizations were generated. The polysynaptic depolarizing potentials reversed at this potential. All records are averages of five nerve-evoked potentials generated at $0.1 \mathrm{~Hz}$. The resting membrane potential $(-65 \mathrm{mV})$ is indicated by the dashed line, and depolarization to $-51 \mathrm{mV}$ is marked by the dotted line. homonymous muscle MG, and the synergistic muscle FDS (Fig. $6 a)$; stimulation of these three nerves induced monosynaptic potentials (Fig. 6b). During motoneuron depolarization the monosynaptic EPSPs triggered action potentials, while depolarization to $-51 \mathrm{mV}$ reversed the polarity of the polysynaptic IPSPs generated by the nerve of the antagonistic muscle EDL (Fig. 6c). It is possible that the long-latency depolarizing IPSPs generated by the synergistic nerve LG/SOL were due to (1) stimulation of the tendon organ afferents (Ib), or (2) formation of inappropriate polysynaptic connections through inhibitory interneurons.

In $17 \%$ of motoneurons with inappropriate monosynaptic innervation, appropriate synapses were not yet established, and homonymous nerve stimulation failed to generate monosynaptic EPSPs. Figure 8 illustrates an EDL motoneuron that was monosynaptically excited by afferents of the antagonistic muscle LG/SOL, while the homonymous afferents of EDL muscle generated polysynaptic IPSPs but failed to evoke monosynaptic EPSPs (Fig. $8 b$ ). The IPSPs reversed at $-49 \mathrm{mV}$ (Fig. $8 d$ ), and were blocked by strychnine (Fig. $8 e$ ).

\section{The specificity of innervation as a function of age}

To examine whether the inappropriate innervation changed during the period of synapse formation, experiments were carried out at the onset of formation of monosynaptic connections (E19E21), during the first $2 \mathrm{~d}$ after birth (P0-P2), and in 3-5-d-old neonates (P3-P5). The percentage of inappropriate monosyn- aptic innervation declined with developmental age (Fig. 9). At E19-E21, 29\% of motoneurons received inappropriate monosynaptic innervation, while at P0-P2 $41 \%$ of motoneurons were inappropriately innervated (Fig. 9). By P3-P5 there was a signiticant decrease in the percentage of motoneurons with inappropriate monosynaptic contacts $(12 \%)$. These findings suggested that, although inappropriate synapses formed initially, the majority of primary afferent-motoneuron synapses were appropriate within a week after birth.

\section{Discussion}

The connectivity pattern between spindle afferents of leg muscles and lumbar motoneurons that innervated these muscles was studied in embryonic and neonatal rats.

\section{Formation of transient inappropriate monosynaptic pathways}

Our findings suggested that the pattern of synaptic pathways changed during spinal cord differentiation. During the early stages of synapse formation a significant percentage of lumbar motoneurons was innervated by afferent projections of their antagonistic muscle nerves. Such synapses were functionally inappropriate because their activation resulted in simultaneous contractions of both homonymous and antagonistic muscles, which prevented coordinated leg movement. The percentage of functionally inappropriate synapses decreased significantly by 3-5 d after birth, when the connectivity pattern of primary afferent projections onto motoneurons was similar to that of 


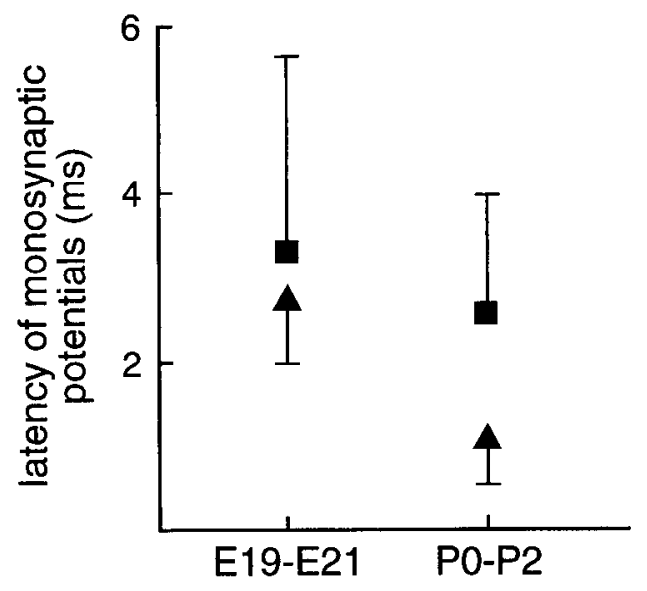

Figure 7. The latencies of appropriate (square) and inappropriate (triangle) monosynaptic potentials as a function of developmental ages. Synaptic latencies were measured as the delays between antidromic action potentials and monosynaptic potentials. In both embryonic (E19E21) and postnatal (P0-P2) motoneurons, the latencies of inappropriate monosynaptic potentials were similar to those of appropriate monosynaptic potentials. Data points are means $\pm \mathrm{SE}$.

mature spinal cords (Eccles et al., 1957a; Mendell and Henneman, 1971; Binder, 1980; Kirkwood and Sears, 1982; Fritz et al., 1989; reviewed by Burke, 1990; Munson, 1990). Our data support preliminary findings indicating that in the spinal cords of 0-10-d-old neonates, the latencies of EPSPs in extensor motoneurons were similar for homonymous and antagonistic nerve stimulation (Navarrete et al., 1987). However, by 4-10 d after birth, primary afferents project to their appropriate motoneurons (Jahr and Yoshioka, 1986).

The conclusions of our study were based on accurate identification of EPSPs as monosynaptic potentials. The criteria used in our study to distinguish between mono- and polysynaptic potentials were the latency of the potentials and their attenuation by repetitive nerve stimulation. If the latency of the potential was the only criterion used, the number of inappropriate connections would have increased by more than $15 \%$. We assumed that the shortest-latency potentials were monosynaptic potentials if repetitive stimulation attenuated their amplitude at least $20 \%$ less than the amplitude of long-latency potentials. Increasing the percentage difference of the fatigue from $20 \%$ to $30 \%$ would have reduced the number of inappropriate synapses by less than $10 \%$.

Our assumptions regarding the specificity of primary afferentmotoneuron contacts were based on the pattern of such synapses in spinal cords of mature cats, because stretch reflex pathways had not been described in adult rats. Therefore, we cannot rule out the possibility that the neuronal pathways in the spinal cord of mature rats are different from that of the cat. However, even if the pattern of innervation is different in the two species, it does not detract from our conclusion that the connectivity between primary afferents and motoneurons significantly changes during the first week after birth.

The mechanisms underlying the increase in percentage of ap-

Figure 8. Inappropriate synapses between afferents of the antagonistic muscle LG/SOL and an EDL motoneuron at E20. $a$, A diagram of appropriate connection between an EDL motoneuron and its homon- a appropriate innervation

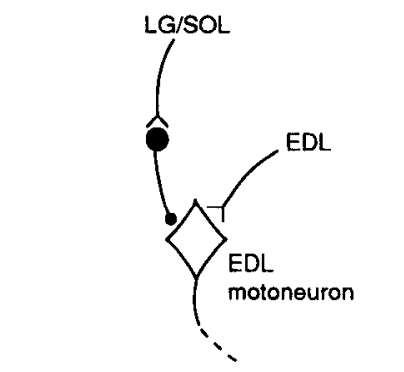

inappropriate innervation

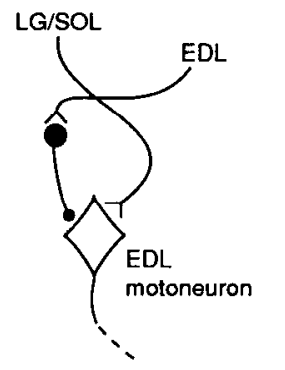

EDL

b resting potential $(-72 \mathrm{mV})$, $0.1 \mathrm{~Hz}$

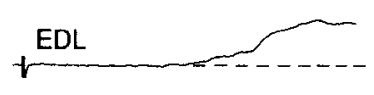

C resting potential, $0.5 \mathrm{~Hz}$
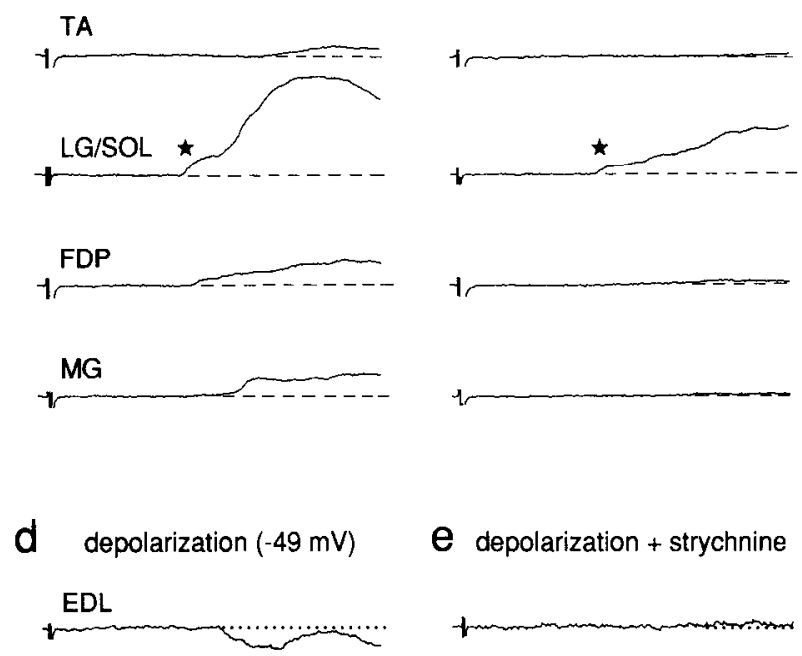

e depolarization + strychnine
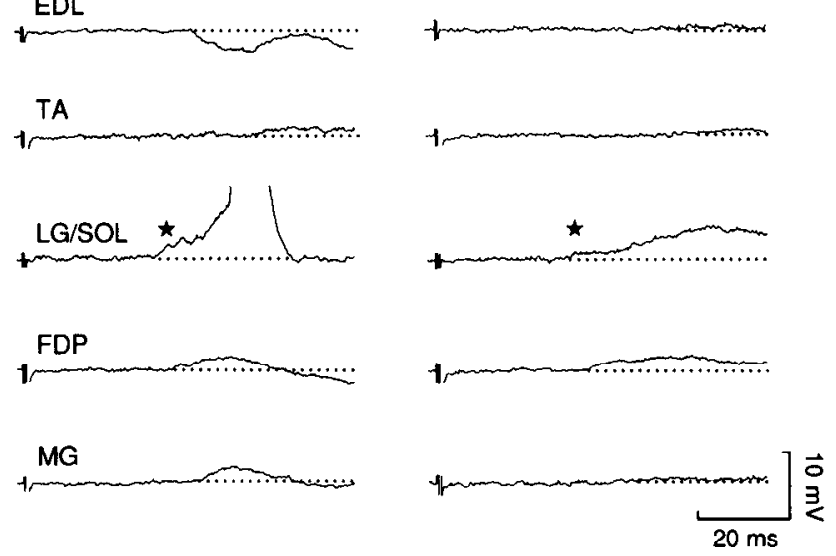

ymous nerve (left) and of inappropriate contact between the EDL motoneuron and the afferents of the antagonistic muscle LG/SOL (right). Inhibitory interneurons are indicated by the solid circles. $b$, Stimulation of LG/SOL produced the shortest-latency potential (star). $c$, Repetitive nerve stimulation at $0.5 \mathrm{~Hz}$ reduced the LG/SOL-evoked potential by about $50 \%$, while the longer-latency potentials generated by all other nerves were either blocked or reduced by at least $70 \%$. $d$, To distinguish between EPSPs and depolarizing IPSPs, the motoneuron was depolarized to $-49 \mathrm{mV}$. Stimulation of the antagonistic nerve LG/SOL triggered an action potential (truncated), while the amplitude of the initial FDP-and MG-evoked potentials did not change significantly. However, the potentials generated by the FDP and MG nerves after a latency of 60 msec and that produced by the homonymous nerve EDL reversed at $-49 \mathrm{mV}$. e, Strychnine $(10 \mu \mathrm{M})$ blocked the potentials that reversed at membrane depolarization, suggesting those were mediated by glycinecontaining inhibitory interneuron. 


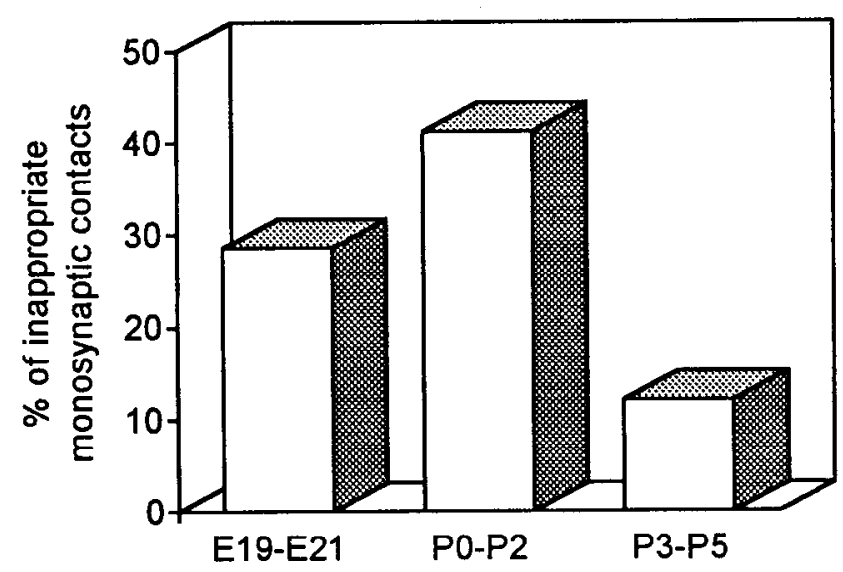

Figure 9. A histogram of the percentage of inappropriate synapses as a function of developmental age. The percentage of inappropriate connections was significantly reduced within a week after birth $(p<0.025)$. At E19-E21, 29\% of the connections were inappropriate $(n=21)$, and $41 \%$ inappropriate synapses were recorded at P0-P2 $(n=34)$. However, by $\mathrm{P} 3-\mathrm{P} 5$ only $12 \%$ of motoneurons were inappropriately innervated by the antagonist nerves $(n=33)$.

propriate innervation during postnatal development are not known. It is possible that (1) functionally inappropriate projections are physically eliminated, or (2) they are not withdrawn but become functionally inactive. A careful electron microscopic study may provide the morphological data necessary to distinguish between the two mechanisms. Electrophysiological studies in spinal cords of mature cats have suggested that the functional state of the connectivity between afferent axons and motoneurons can be modulated by recruiting existent but inactive synapses (reviewed by Lüscher, 1990). Evidence for the existence of inactive connections requires stimulation of identified single primary afferents (reviewed by Mendell el al., 1990), which is difficult to perform in developing spinal cords of rats.

\section{Phylogenetic differences between rats, chicks, and frogs}

The reasons for the initial formation of functionally inappropriate synapses in the rat but not in the frog or chick are not well understood, but the inability of embryonic and neonatal rats to execute coordinated limb movements may be advantageous to their development. The absence of coordinated limb movements may prevent them from harming nearby embryos, and increase their chances of staying near the mother for nursing.

A number of phylogenetic differences in the pattern and time course of neuronal differentiation may contribute to the different pattern of synaptogenesis in rats and other vertebrates. A possible explanation for the differences between species is that functionally inappropriate innervation in the rat is due to low level of synaptic activity in spinal cords of embryonic rats. Neural activity influences the development of the vertebrate nervous system (reviewed by Fields and Nelson, 1992; Groodman and Shatz, 1993), and it plays a major role in the establishment of appropriate connectivity in the visual system (Hubel and Wiesel, 1970; Stryker and Harris, 1986; Dubin et al., 1988; Simon et al., 1992). The effect of neuronal activity was examined in chick and frog spinal cords, where disrupting the pattern of coordinated muscle and neural activities did not affect the formation of appropriate sensorimotor contacts (Frank, 1990; Mendelson and Frank, 1991). However, the role of interneuronal activity in the formation of appropriate synapses was not studied in developing spinal cords. It is possible that high-frequency spontaneous activity, like the patterns recorded in embryonic chick spinal cords (O'Donovan, 1989), influences the formation of specific connectivity in the chicks. In the spinal cord of embryonic rats, the level of spontancous activity is low despite the early formation of both neuromuscular contacts (E15E16, Dennis et al., 1981) and monosynaptic connections (E17E18, Saito, 1979; Kudo and Yamada, 1987; Ziskind-Conhaim, 1990). Spontaneous activity may be low due to inhibitory pathways that are predominant at the onset of the formation of sensorimotor synapses (Wu et al., 1992). The significant increase in spontaneous activity within $1-2 \mathrm{~d}$ after birth (B. S. Seebach and L. Ziskind-Conhaim, unpublished observations) was temporally correlated with the reduction in the percent of inappropriate synapses.

Another factor that may contribute to the formation of inappropriate spinal synapses is the slower time course of myelination in mammals. In rats, myelination begins at birth (Ziskind-Conhaim, 1988b), while in chicks and tadpoles peripheral nerves are at least partially myelinated during the period of formation of sensorimotor contacts (Carpenter and Berg, 1957; Frank and Westerfield, 1983). It is possible that nonmyelinated nerves are physically less constrained than myelinated nerves, and the probability of afferent projections deviating from their pathways to the appropriate motoneurons may thus be higher in the rat than in chicks or frogs. Numerous studies have described the initial growth of dorsal root axons into the motor nuclei of spinal cords of rat embryos (Kudo and Yamada, 1987; Ziskind-Conhaim, 1990; Snider et al., 1992), but more comprehensive studies will be necessary to characterize the growth pattern of homonymous muscle afferent projections onto their motoneurons.

Our findings suggested that transient, functionally inappropriate sensorimotor synapses were formed in the spinal cords of rat embryos, but their functional contribution to reflex pathways declined within a few days after birth. The delayed formation of appropriate connections may explain the inability of neonatal rats to execute coordinated limb movements.

\section{References}

Baldissera F, Hultborn H, Illert M (1981) Integration in spinal neuronal systems. In: Handbook of physiology (Brookhart JM, Mountcastle VB, eds), pp 509-595. Baltimore: Williams and Wilkins.

Berry MS, Pentreath VW (1976) Criteria for distinguishing between monosynaptic and polysynaptic transmission. Brain Res 105:1-20.

Binder MD (1980) Topographic organization of monosynaptic reflexes in the cat spinal cord. Neurosci Lett 20:121-124.

Burke RE (1990) Spinal cord: ventral horn. In: The synaptic organization of the brain, 3d ed (Shepherd GM, ed), pp 88-132. New York: Oxford UP.

Carpenter FG, Berg RM (1957) Excitation and conduction in immature nerve fibers of the developing chick. Am J Physiol 190:371376.

Dennis MJ, Ziskind-Conhaim L, Harris AJ (1981) Development of neuromuscular junctions in rat embryos. Dev Biol 81:266-279.

Dubin MW, Stark LA, Archer SM (1986) A role for action-potential activity in the development of neuronal connections in the kitten retinogeniculate pathway. J Neurosci 6:1021-1036.

Eccles JC, Eccles RM, Lundberg A (1957a) The convergence of monosynaptic excitatory afferents on to many different species of alpha motoneurones. J Physiol (Lond) 137:22-50.

Eccles JC, Eccles RM, Lundberg A (1957b) Synaptic actions on motoneurons caused by impulses on Golgi tendon organ afferents. J Physiol (Lond) 138:227-252.

Eide A-L, Jansen JKS, Ribchester RR (1982) The effect of lesions in the neural crest on the formation of synaptic connexions in the embryonic chick spinal cord. J Physiol (Lond) 324:453-478. 
Fields RD, Nelson PG (1992) Activity-dependent development of the vertebrate nervous system. Int.Rev Neurobiol 34:133-214.

Frank F. (1990) The formation of specific synaptic connections between muscle sensory and motor neurons in the absence of coordinated patterns of muscle activity. J Neurosci 10:2250-2260.

Frank E, Westerfield M (1982) Synaptic organization of sensory and motor neurones innervating triceps brachii muscles in the bullfrog. $\mathbf{J}$ Physiol (Lond) 324:479-494.

Frank E, Westerfield M (1983) Development of sensory-motor synapses in the spinal cord of the frog. J Physiol (Lond) 343:593-610.

Fritz N, Illert M, de la Motte S, Reeh P, Saggau P (1989) Pattern of monosynaptic la connections in the cat forelimb. J Physiol (Lond) 419:321-351.

Gao B-X, Ziskind-Conhaim L (1992) Glycine- and GABA-activated currents in motoneurons of developing rat spinal cord. Soc Neurosci Abstr 18:610.

Goodman CS, Shatz CJ (1993) Developmental mechanisms that generate precise patterns of neuronal connectivity. Cell 72:77-98.

Hubel DH, Wiesel TN (1970) The period of susceptibility to the physiological effects of unilateral eye closure in kittens. J Physiol (Lond) 206:419-436.

Jahr CE, Yoshioka K (1986) Ia afferent excitation of motoneurones in the in vitro new-born rat spinal cord is selectively antagonized by kynurenate. J Physiol (Lond) 370:515-530.

Kirkwood PA, Sears TA (1982) Excitatory post-synaptic potentials from single muscle spindle afferents in external intercostal motoneurones of the cat. J Physiol (Lond) 322:287-314.

Kudo N, Yamada T (1985) Development of the monosynaptic stretch reflex in the rat: an in vitro study. J Physiol (Lond) 369:127-144.

Kudo N, Yamada T (1987) Morphological and physiological studies of development of the monosynaptic reflex pathway in the rat lumbar spinal cord. J Physiol (Lond) 389:441-459.

Kuno M (1964) Quantal components of excitatory synaptic potentials in spinal motoneurones. J Physiol (Lond) 175:81-99.

Lee MT, O’Donovan MJ (1991) Organization of hindlimb muscle afferent projections to lumbosacral motoneurons in the chick embryo. J Neurosci 11:2564-2573.

Lee MT, Koebbe MJ, O'Donovan MJ (1988) The development of sensorimotor synaptic connections in the lumbosacral cord of the chick embryo. J Neurosci 8:2530-2543.

Lüscher H-R (1990) Transmission failure and its relief in the spinal monosynaptic reflex arc. In: The segmental motor system (Binder MD, Mendell LM, eds), pp 328-348. New York: Oxford UP.

Mendell LM, Henneman E (1971) Terminals of single Ia fibers: location, density and distribution within a pool of 300 homonymous motoneurons. J Neurophysiol 34:171-187.

Mendell LM, Collins WF, Koerber HR (1990) How are Ia synapses distributed on spinal motoneurons to permit orderly recruitment? In: The segmental motor system (Binder MD, Mendell LM, eds), pp 308327. New York: Oxford UP.
Mendelson B, Frank E (1991) Specific monosynaptic sensory-motor connections form in the absence of patterned neural activity and motoneuronal cell death. J Neurosci 11:1390-1403.

Munson JB (1990) Synaptic inputs to type-identified motor units. In: The segmental motor system (Binder MD, Mendell LM, eds), pp 291307. Ncw York: Oxford UP.

Navarrete R, Walton K, Llinas R (1987) Spinal network development and its relation to hindlimb movement: an in vitro electrophysiological study in neonatal rat. Soc Neurosci Abstr 13:824.

O'Donovan MJ (1989) Motor activity in the isolated spinal cord of the chick embryo: synaptic drive and firing pattern of single motoneurons. J Neurosci 9:943-958.

Peters A, Muir AR (1959) The relationship between axons and Schwann cells during development of peripheral nerves in the rat. $Q J$ Exp Physiol 64:117-130.

Saito K (1979) Development of spinal reflexes in the rat fetus studied in vitro. J Physiol (Lond) 294:581-594.

Seebach BS, Ziskind-Conhaim L (1992) Specificity of synaptic connections between muscle afferents and motoneurons in the developing rat spinal cord. Soc Neurosci Abstr 18:947.

Simon DK, Prusky GT, O'Leary DDM, Constantine-Paton M (1992) $N$-methyl-D-aspartate receptor antagonists disrupt the formation of a mammalian neural map. Proc Natl Acad Sci USA 89:10593-10597.

Snider WD, Zhang L, Yusoof S, Gorukanti N, Tsering C (1992) Interactions between dorsal root axons and their target motor neurons in developing mammalian spinal cord. J Neurosci 12:3494-3508.

Stryker MP, Harris WA (1986) Binocular impulse blockade prevents the formation of ocular dominance columns in cat visual cortex. J Neurosci 6:2117-2133.

Takahashi $T$ (1984) Inhibitory miniature synaptic potentials in rat motoneurones. Proc R Soc I ond [Biol] 2.21:103-109.

Walton KD, Navarrete $\mathrm{R}$ (1991) Postnatal changes in motoneurone electrotonic coupling studied in the in vitro rat lumbar spinal cord. J Physiol (Lond) 433:283-305.

Wu W-1, Ziskind-Conhaim L, Sweet MA (1992) Early development of glycine- and GABA-mediated synapses in rat spinal cord. J Neurosci 12:3935-3946.

Ziskind-Conhaim L (1988a) Electrical properties of motoneurons in the spinal cord of rat embryos. Dev Biol 128:21-29.

Ziskind-Conhaim L (1988b) Physiological and morphological changes in developing peripheral nerves of rat embryos. Dev Brain Res 42: $15-28$.

Ziskind-Conhaim L (1990) NMDA receptors mediate poly- and monosynaptic potentials in motoneurons of rat embryos. J Neurosci $10: 125-135$.

Ziskind-Conhaim L, Seebach BS, Gao B-X (1993) Changes in serotonin-induced potentials during spinal cord development. J Neurophysiol 69:1338-1349. 